\title{
Comparison of the multifractal characteristics of heavy metals in soils within two areas of contrasting economic activities in China
}

\author{
Xiaohui Li ${ }^{1,2}$, Xiangling Li ${ }^{1}$, Feng Yuan ${ }^{1,2}$, Simon M. Jowitt ${ }^{3,4}$, Taofa Zhou ${ }^{1}$, Kui Yang ${ }^{1}$, Jie Zhou ${ }^{1}$, Xunyu Hu ${ }^{1}$, and \\ Yang $\mathbf{L i}{ }^{1}$ \\ ${ }^{1}$ School of Resources and Environmental Engineering, Hefei University of Technology, Hefei 230009, China \\ ${ }^{2}$ Xinjiang Research Centre for Mineral Resources, Xinjiang Institute of Ecology and Geography, \\ Chinese Academy of Sciences, Urumqi, Xinjiang 830011, China \\ ${ }^{3}$ School of Earth, Atmosphere and Environment, Monash University, Wellington Road, Clayton, VIC 3800, Australia \\ ${ }^{4}$ Department of Geoscience, University of Nevada Las Vegas, 4505 S. Maryland Parkway, Las Vegas, NV 89154-4010, USA \\ Correspondence to: Feng Yuan (yf_hfut@163.com)
}

Received: 26 January 2016 - Published in Nonlin. Processes Geophys. Discuss.: 25 February 2016

Revised: 2 August 2016 - Accepted: 3 August 2016 - Published: 6 September 2016

\begin{abstract}
Industrial and agricultural activities can generate heavy metal pollution that can cause a number of negative environmental and health impacts. This means that evaluating heavy metal pollution and identifying the sources of these pollutants, especially in urban or developed areas, is an important first step in mitigating the effects of these contaminating but necessary economic activities. Here, we present the results of a heavy metal $(\mathrm{Cu}, \mathrm{Pb}, \mathrm{Zn}, \mathrm{Cd}, \mathrm{As}$, and $\mathrm{Hg})$ soil geochemical survey in Hefei city. We used a multifractal spectral technique to identify and compare the multifractality of heavy metal concentrations of soils within the industrial Daxing and agricultural Yicheng areas. This paper uses three multifractal parameters $\left(\Delta \alpha, \Delta f(\alpha)\right.$, and $\left.\tau^{\prime \prime}(1)\right)$ to indicate the overall amount of multifractality within the soil geochemical data. The results show all of the elements barring $\mathrm{Hg}$ have larger $\Delta \alpha, \Delta f(\alpha)$, and $\tau^{\prime \prime}(1)$ values in the Daxing area compared to the Yicheng area. The degree of multifractality suggests that the differing economic activities in Daxing and Yicheng generate very different heavy metal pollution loads. In addition, the industrial Daxing area contains significant $\mathrm{Pb}$ and $\mathrm{Cd}$ soil contamination, whereas $\mathrm{Hg}$ is the main heavy metal present in soils within the Yicheng area, indicating that differing clean-up procedures and approaches to remediating these polluted areas are needed. The results also indicate that multifractal modelling and the associated generation of multifractal parameters can be a useful approach in the evaluation of heavy metal pollution in soils.
\end{abstract}

\section{Introduction and overview of the study area}

Heavy metal pollution within soil poses a serious risk for human health and the environment, and thus soil pollution caused by anthropogenic activities (including industry and agriculture) has been the focus of a significant amount of research (e.g. Leyval et al., 1997; Thomas and Stefan, 2002; McGrath et al., 2004; Wang et al., 2007; Luo et al., 2011). Analysing soil geochemistry and pollution using multifractal techniques may allow for assessing many of the problems of non-linear variability which commonly arise when dealing with pollutants, as well as enabling the identification of non-linear characteristics within data sets. This approach can yield new information that can be used to understand the factors controlling the distribution of key elements within the objects or data being studied (Salvadori, 1997; Gonçalves, 2000; Zuo et al., 2012). This in turn means that determining the multifractal characteristics of the distribution of heavy metals in soils can improve our understanding of any heavy metal pollution that is associated with these differing anthropogenic activities.

Multifractal techniques include singularity mapping and multifractal interpolation that enable more detailed analysis of the spatial distribution of heavy metals, concentrationarea modelling that can be used to define threshold values between background (i.e. geological) and anthropogenic anomalies (Lima et al., 2003), spectral density-area modelling that can be used to define thresholds to separate 
anomalies (i.e. anthropogenically derived heavy metal concentrations in this case) from background concentrations (i.e. geologically derived heavy metal concentrations; Cheng, 2001), and multifractal spectra that highlight non-linear characteristics and identify anomalous behaviour that reflects the characteristics of some multifractal sets (Gonçalves, 2000; Albanese et al., 2007; Guillén et al., 2011), such as the presence of porous structures and spatial variations in soil properties (Caniego et al., 2005; Dathe et al., 2006). This means that multifractal techniques can be useful tools for the analysis of heavy metal pollution within soils (e.g. Salvadori et al., 1997; Lima et al., 2003; Albanese et al., 2007; Guillén et al., 2011). These multifractal techniques are used not only in environmental science but also in a number of differing fields, including geophysics (Schertzer et al., 2011), medicine (Jennane et al., 2001), computer science (Wendt et al., 2009), geology (Cheng, 1995; Deng et al., 2011; Yuan et al., 2012, 2015), and ecology (Pascual et al., 1995), among others.

Hefei is the capital of Anhui Province, China, and has an urban area that includes the towns of Daxing and Yicheng, which focus on industrial and agricultural activities, respectively. Here, we use multifractal spectra techniques and three parameters $\left(\Delta \alpha, \Delta f(\alpha)\right.$, and $\left.\tau^{\prime \prime}(1)\right)$ to analyse and compare the degree and characteristics of the multifractality of heavy metal contamination in soils associated with anthropogenic activities in this region. The results will further enable and inform future planning for any necessary remediation of the soils in the Daxing and Yicheng areas.

\section{Study area and geochemical data}

\subsection{Study area}

The city of Hefei is situated in central-eastern China (Fig. 1a), has approximately 7.7 million inhabitants, and covers an area of around $11408 \mathrm{~km}^{2}$. This paper focuses on the towns of Daxing and Yicheng (Fig. 1b), with the former representing one of the traditional industrial areas of Hefei and containing numerous factories that are involved in the steel industry, chemical industry, paper making, and the production of furniture and construction materials, among others. In contrast, the town of Yicheng focuses its economic activities on agricultural production, byproduct processing, livestock and poultry breeding, ornamentals, and other enterprises related to agricultural activity.

\subsection{Sampling and analysis}

The study areas are covered by Quaternary sedimentary soils and are free of both natural mineralization and miningrelated contamination. A total of 169 surface $(<20 \mathrm{~cm}$ depth) soil samples were taken from the towns of Daxing and Yicheng on $1 \mathrm{~km} \times 1 \mathrm{~km}$ grids, yielding 78 samples from Daxing and 91 samples from Yicheng (Fig. 1c, d). Sam-
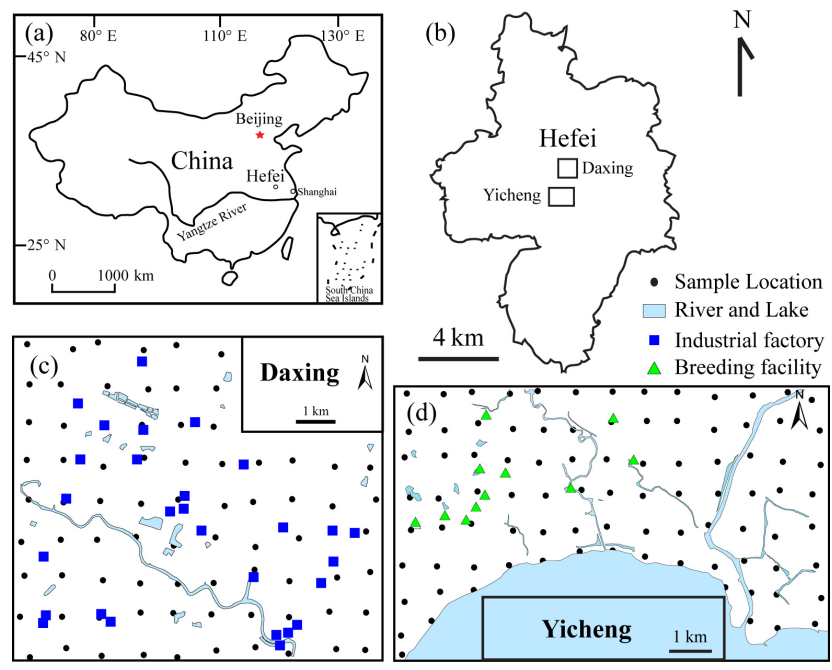

Figure 1. Location of Hefei in central-eastern China (a); location of the study areas within Hefei (b); the $1 \mathrm{~km} \times 1 \mathrm{~km}$ grids used for soil sampling in the towns of Daxing (c) and Yicheng (d).

pling errors were minimized by splitting each sample into three to five sub-samples, each of which weighed more than $500 \mathrm{~g}$. Each of these sub-samples was air-dried before being broken up using a wooden roller and then sieved to pass through a $0.85 \mathrm{~mm}$ mesh. The concentrations of six heavy metal elements $(\mathrm{Cu}, \mathrm{Pb}, \mathrm{Zn}, \mathrm{Cd}, \mathrm{As}$, and $\mathrm{Hg}$ ) were determined during this study, with $\mathrm{Cd}, \mathrm{Cu}, \mathrm{Pb}$, and $\mathrm{Zn}$ concentrations determined by inductively coupled plasma-mass spectrometry (ICP-MS), whereas $\mathrm{Hg}$ and As concentrations were determined by hydride generation-atomic fluorescence spectrometry (AFS; Armstrong et al., 1999; Gómez-Ariza et al., 2000). These techniques have detection limits of $1 \mathrm{ppm}$ for $\mathrm{Cu}, 2 \mathrm{ppm}$ for $\mathrm{Pb}$ and $\mathrm{Zn}, 30 \mathrm{ppb}$ for $\mathrm{Cd}, 0.5 \mathrm{ppm}$ for As, and $5 \mathrm{ppb}$ for Hg. The accuracy of these data was monitored by repeat and replicate determinations using instrumental neutron activation analysis (INAA), with analytical precision monitored using variance of the results obtained from duplicate analyses.

\section{Multifractal spectrum analysis}

Multifractal formalisms can decompose self-similar measures into intertwined fractal sets that are characterized by singularity strength and fractal dimensions (Cheng, 1999). Using multifractal techniques allows non-linear characteristics within data sets to be identified, enabling the extraction of information that can be used to understand the factors controlling the distribution of key elements within the data. Fractal spectra $(f(\alpha))$ are formalisms that can be used to describe the multifractal characteristics of a data set and can be estimated using box-counting, gliding-box, histogram, and wavelet methods, among others (Cheng, 1999; Lopes and Betrouni, 2009). The most widely used of these methods are 
the box-counting and gliding-box methods, both of which are based on the moment method.

The calculation of the mass exponent function $\tau(q)$ for the gliding-box method is different from the box-counting method, with the gliding-box method providing a useful approach that can increase the number of samples that are available for statistical estimation within a data set (Buczkowski et al., 1998; Tarquis et al., 2006; Xie et al., 2010). This means that the gliding-box approach often provides better results with lower uncertainties than the box-counting method (Cheng, 1999). As such, we have used the gliding-box approach during this study. The calculation of the mass exponent function $\tau(q)$ for the gliding-box method uses a partition function as follows (Cheng, 1999):

$$
\begin{aligned}
\langle\tau(q)\rangle+D & =\lim _{\varepsilon \rightarrow 0}\left(\frac{\log \left(\mu^{q}(\varepsilon)\right)}{\log (\varepsilon)}\right) \\
& =\lim _{\varepsilon \rightarrow 0}\left(\frac{\log \left(\frac{1}{N^{*}(\varepsilon)}\right) \sum_{i=1}^{N^{*}(\varepsilon)} \mu_{i}^{q}(\varepsilon)}{\log (\varepsilon)}\right),
\end{aligned}
$$

where $\mu_{i}(\varepsilon)$ denotes a measure with the $i$ th cell of a gliding box of size $\varepsilon, q$ is the order moment of this measure (this paper used a range of $q$ values from -10 to 10 with an interval of 1$),<>$ indicates the statistical moment, and $N^{*}(\varepsilon)$ indicates the total number of gliding boxes of size $\varepsilon$ with $\mu_{i}(\varepsilon)$ values different from 0 .

The values of $\tau(q)$ derived using this equation can be then used to determine singularity $\alpha$ and fractal spectra $f(\alpha)$ values using a Legendre transformation, as expressed below:

$$
\begin{aligned}
& \alpha(q)=\frac{\mathrm{d} \tau(q)}{\mathrm{d} q}, \\
& f(\alpha)=q \alpha(q)-\tau(q)=q \frac{\mathrm{d} \tau(q)}{\mathrm{d} q}-\tau(q) .
\end{aligned}
$$

$\Delta \alpha$ and $\Delta f$ are essential parameters required to analyse the multifractal characteristics of a given data set. The widths of the left $\left(\Delta \alpha_{\mathrm{L}}\right)$ and right $\left(\Delta \alpha_{\mathrm{R}}\right)$ branches within the multifractal spectra are then defined using the following equations:

$$
\begin{aligned}
& \Delta \alpha_{\mathrm{L}}=\alpha_{0}-\alpha_{\min }, \\
& \Delta \alpha_{\mathrm{R}}=\alpha_{\max }-\alpha_{0}, \\
& \Delta \alpha=\alpha_{\max }-\alpha_{\min } .
\end{aligned}
$$

The height difference $\Delta f(\alpha)$ between the two ends of the multifractal spectrum is then extracted using

$\Delta f(\alpha)=f\left(\alpha_{\max }\right)-f\left(\alpha_{\min }\right)$.

Higher $\Delta \alpha$ and $\Delta f(\alpha)$ values are generally indicative of data sets with more heterogeneous patterns (ordered, complex, clustered) and higher levels of multifractality (Cheng, 1999; Kravchenko et al., 1999). In addition, local multifractality $\tau^{\prime \prime}(1)$, which may determined by ordinary spatial analysis functions (autocorrelations and semivariograms), can also be used as a measure to quantitatively characterize the multifractality of a data set using Eq. (8) (Cheng, 2006):

$\tau^{\prime \prime}(1)=\tau(2)-2 \tau(1)+\tau(0)$,

$\Delta f(\alpha)=f\left(\alpha_{\max }\right)-f\left(\alpha_{\min }\right)$.

If $\mu$ is a multifractal and $-D<\tau^{\prime \prime}(1)<0$, where $D$ is the gliding-box dimension, then more negative values of $\tau^{\prime \prime}(1)$ are indicative of higher degrees of multifractality, whereas otherwise $\tau^{\prime \prime}(1)=0$ for monofractal.

\section{Geochemical analysis results}

A statistical summary of the soil geochemical data for the study area is given in Table 1. Samples from the Daxing area have higher $\mathrm{Cu}, \mathrm{Pb}, \mathrm{Zn}, \mathrm{Cd}$, and As maximum, mean, standard deviation, skewness, and kurtosis values than soil samples from the Yicheng area, whereas the Yicheng area has a higher maximum $\mathrm{Hg}$ concentration value than the Daxing area. In addition, the soil samples from Daxing have much higher coefficient of variation $(\mathrm{CV})$ values for $\mathrm{Cu}, \mathrm{Pb}, \mathrm{Zn}$, $\mathrm{Cd}$, and As than the samples from the Yicheng area, indicating that soils in the Daxing area contain higher and more variable concentrations of these elements. This also suggests that samples from the Daxing area containing elevated concentrations of heavy metals were probably contaminated by anthropogenic activity.

All of the elements (barring $\mathrm{Pb}$ and $\mathrm{Cu}$ in the Yicheng area) in both the Yicheng and Daxing areas yielded concentration histograms that are positively skewed and contain some outliers (Fig. 2), indicating that these data have non-normal and potentially fractal- or multifractal-type distributions. This means that multifractal techniques are highly suited for the characterization of the geochemistry of the soils.

\section{Calculation processes of multifractal spectrum and discussion}

The multifractal spectra (in the form of an $\alpha-f(\alpha)$ diagram) for the geochemical data are shown in Fig. 3.

These multifractal spectra have inverse bell shapes (Fig. 3) and are asymmetric (i.e. $\Delta \alpha_{\mathrm{L}}$ values significantly differ from $\Delta \alpha_{\mathrm{R}}$, Eqs. 5-6), with the exception of the $\mathrm{Cu}$ data for soils from the Yicheng area, indicating that the samples containing low and high concentrations of these elements are not evenly distributed within the study area (as is expected for areas containing point source pollutants like factories or animal breeding facilities).

The multifractal results given in Table 2 indicate that all of the elements (barring $\mathrm{Cu}$ and $\mathrm{Pb}$ in the Yicheng area) are 
Table 1. Summary statistics of soil heavy metal concentrations within samples from the Daxing and Yicheng areas.

\begin{tabular}{|c|c|c|c|c|c|c|c|c|}
\hline \multirow[t]{2}{*}{ Town } & \multirow[t]{2}{*}{ Element } & Min & Max & Mean & Standard deviation & Skewness & Kurtosis & \multirow{2}{*}{$\frac{\mathrm{CV}^{*}}{(\%)}$} \\
\hline & & \multicolumn{3}{|c|}{$\left(\mathrm{mg} \mathrm{kg}^{-1}\right)$} & \multicolumn{3}{|c|}{$(-)$} & \\
\hline \multirow{6}{*}{ 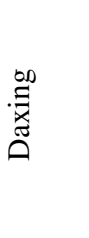 } & $\mathrm{Cu}$ & 19.00 & 111.50 & 33.87 & 13.26 & 3.20 & 14.93 & 39.16 \\
\hline & $\mathrm{Pb}$ & 18.90 & 291.30 & 39.57 & 35.03 & 5.37 & 35.41 & 88.51 \\
\hline & $\mathrm{Zn}$ & 40.90 & 526.10 & 105.8 & 94.40 & 2.91 & 8.59 & 89.19 \\
\hline & $\mathrm{Cd}$ & 0.045 & 1.48 & 0.23 & 0.24 & 3.45 & 13.81 & 108.23 \\
\hline & As & 4.93 & 308.20 & 13.97 & 33.89 & 8.72 & 76.64 & 242.56 \\
\hline & $\mathrm{Hg}$ & 0.03 & 0.60 & 0.11 & 0.11 & 2.68 & 7.78 & 107.29 \\
\hline \multirow{6}{*}{$\begin{array}{l}\infty 00 \\
\bar{D} \\
\bar{D} \\
\vdots\end{array}$} & $\mathrm{Cu}$ & 9.60 & 37.80 & 24.34 & 5.77 & -0.38 & 0.41 & 23.71 \\
\hline & $\mathrm{Pb}$ & 10.40 & 46.30 & 22.77 & 4.91 & 0.87 & 5.51 & 21.56 \\
\hline & $\mathrm{Zn}$ & 20.80 & 194.80 & 54.70 & 21.43 & 3.45 & 20.27 & 39.17 \\
\hline & $\mathrm{Cd}$ & 0.054 & 0.43 & 0.15 & 0.08 & 1.84 & 3.49 & 51.85 \\
\hline & As & 2.30 & 44.20 & 7.29 & 4.39 & 6.68 & 56.55 & 60.24 \\
\hline & $\mathrm{Hg}$ & 0.02 & 0.62 & 0.06 & 0.07 & 5.75 & 41.26 & 113.09 \\
\hline
\end{tabular}

* CV: coefficient of variation
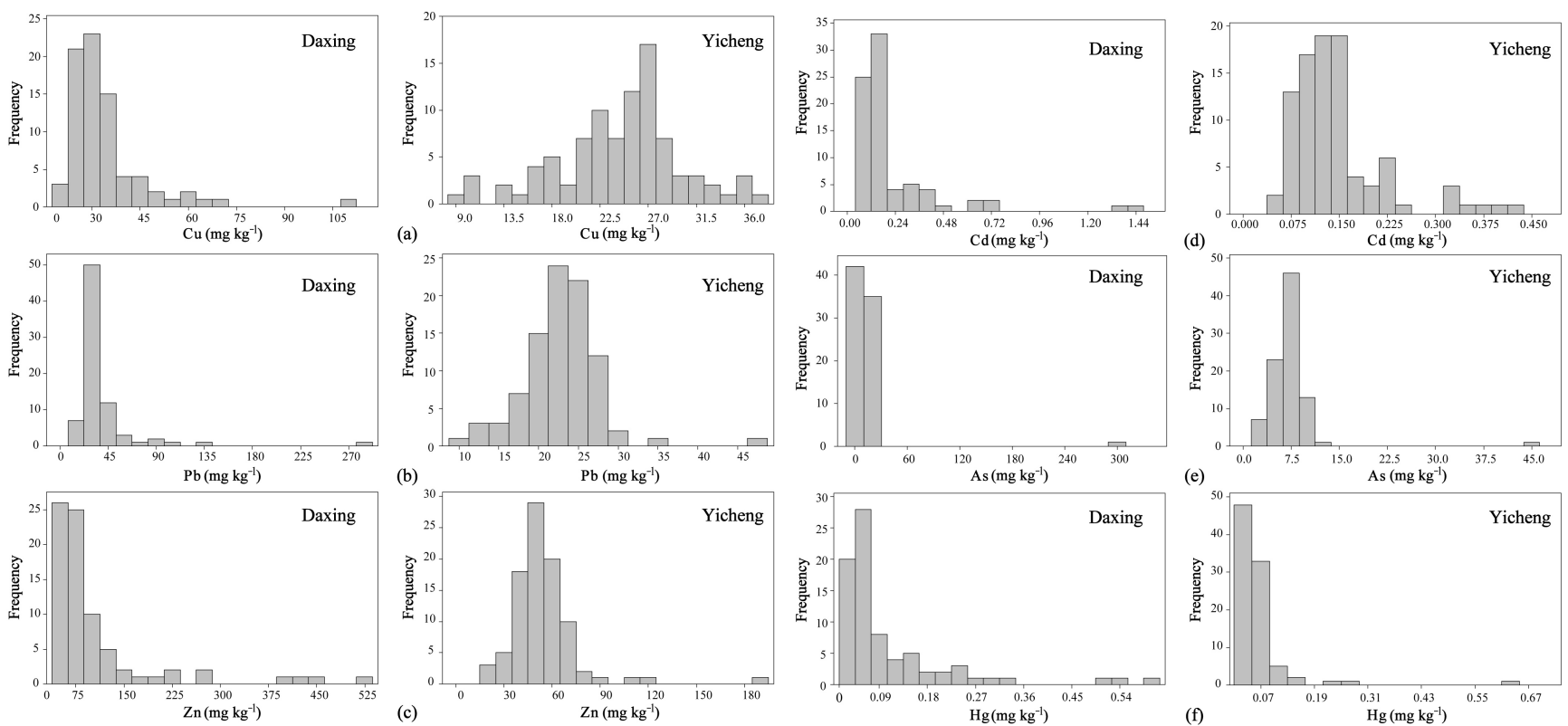

Figure 2. Histograms showing the distribution of $\mathrm{Cu}(\mathbf{a}), \mathrm{Pb}(\mathbf{b}), \mathrm{Zn}(\mathbf{c}), \mathrm{Cd}(\mathbf{d}), \mathrm{As}(\mathbf{e})$, and $\mathrm{Hg}(\mathbf{f})$ concentrations within soils from the towns of Daxing and Yicheng.

characterized by a wide range of $\alpha$ values, with $\tau^{\prime \prime}(1)$ values less than -0.01 and $\Delta f(\alpha)$ values larger than 0.5 , all of which indicate that these elements have a high multifractality within the soils in these two areas. All of the elements analysed during this study (barring $\mathrm{Hg}$ ) have higher $\Delta f(\alpha)$ and $\alpha$ values (except $\mathrm{Zn}$ ) and lower $\tau^{\prime \prime}(1)$ values in soils from the Daxing area, with $\mathrm{Hg}$ having higher $\Delta f(\alpha)$ and $\Delta \alpha$ and lower $\tau^{\prime \prime}(1)$ values in soils from the Yicheng area (Table 2). This suggests that the industrial activities in the Daxing area generate multi-element heavy metal soil contamination, whereas the most significant heavy metal pollution associated with the agricultural activity in the Yicheng area is $\mathrm{Hg}$ contamination. The $\Delta f(\alpha)$ and $\Delta \alpha$ values of $\mathrm{Hg}$ in the Yicheng area are larger than the values for all other elements in this area as well as some of the elements in the Daxing area, indicating both the prevalence and significant degree of agricultural $\mathrm{Hg}$ contamination in the Yicheng area, even considering the lower overall concentrations of $\mathrm{Hg}$ within the Yicheng area compared to the Daxing area. This contamination should be considered a priority in terms of remediation, because the interaction between the agricultural activity in the Yicheng area and this $\mathrm{Hg}$ pollution could seriously impact human health, as $\mathrm{Hg}$ is preferentially concentrated upward in the food chain (e.g. Jiang et al., 2006). This means 

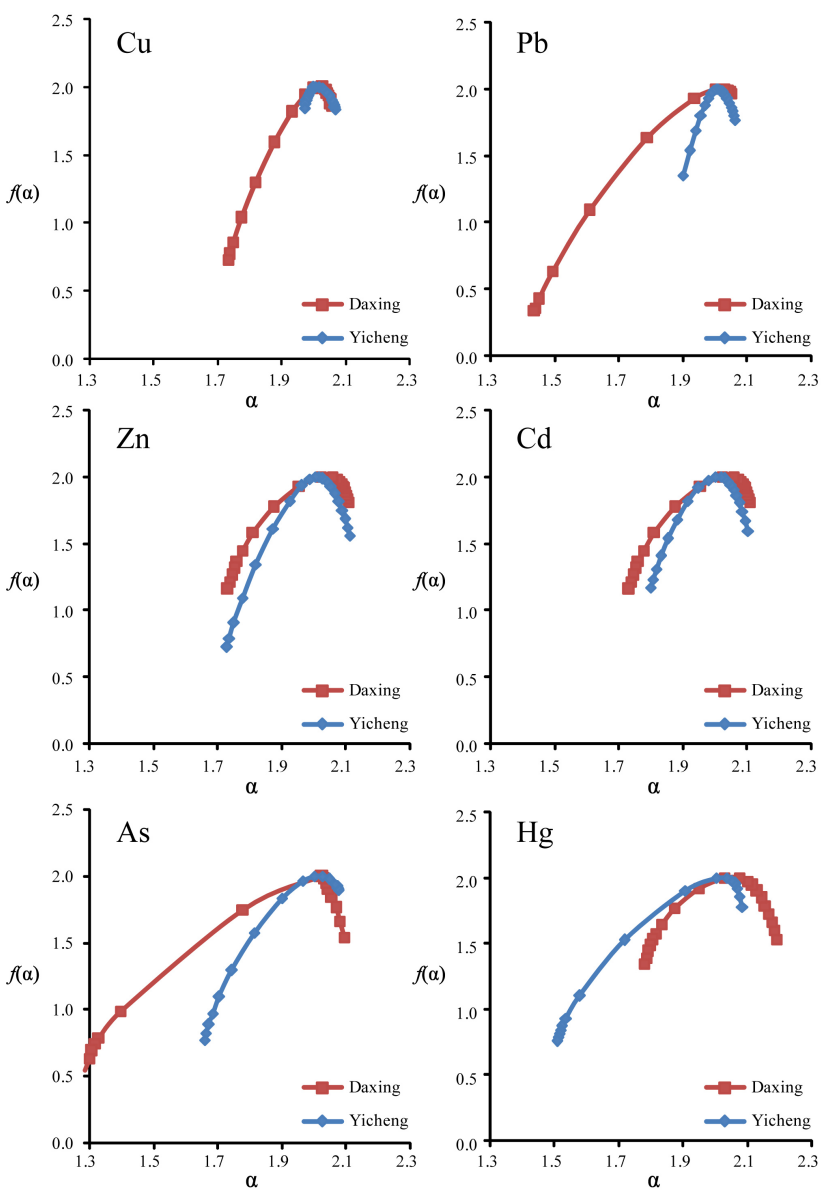

Figure 3. Multifractal spectra ( $f(\alpha)$ vs. $\alpha$ ) of the soil geochemical data from the Daxing and Yicheng areas.

that, although contamination in both areas needs to be evaluated further and should be remediated to avoid any deleterious effects, the fact that the $\mathrm{Hg}$ contamination in the Yicheng area may be more bioavailable and may have a larger effect on the population of this region (as a result of the agricultural activity in this area) means it should be considered a priority.

In order to compare variations in multifractality, the elements within the samples from the Daxing and Yicheng areas were sorted by $\Delta \alpha, \Delta f(\alpha)$, and $\tau^{\prime \prime}(1)$ parameters, in addition to sorting by coefficient of variation values (Table 3 ). The data shown in Table 3 indicate that the $\mathrm{Pb}$ data within the Daxing area have close to the lowest coefficient of variation, but the largest $\Delta f(\alpha)$ and $\tau^{\prime \prime}(1)$ values for these $\mathrm{Pb}$ data are indicative of strongest multifractality compared to the other heavy metals in the soils within the Daxing area. In comparison, the As data for soils in the Daxing area yielded the largest coefficient of variation but moderate $\Delta f(\alpha)$ and $\tau^{\prime \prime}(1)$ values, indicating these As data only have moderate multifractality. These differences indicate that the multifractal parameters reveal new information about the non-linear variability and the characteristics of these geochemical data
Table 2. Multifractal parameters of the elements analysed during this study.

\begin{tabular}{|c|c|c|c|c|c|c|c|c|}
\hline Town & Element & $\alpha_{\min }$ & $\alpha_{\max }$ & $\Delta \alpha_{\mathrm{L}}$ & $\Delta \alpha_{\mathrm{R}}$ & $\Delta \alpha$ & $\Delta f(\alpha)$ & $\tau^{\prime \prime}(1)$ \\
\hline \multirow{6}{*}{ 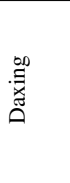 } & $\mathrm{Cu}$ & 1.733 & 2.057 & 0.280 & 0.044 & 0.324 & 1.270 & -0.015 \\
\hline & $\mathrm{Pb}$ & 1.439 & 2.050 & 0.567 & 0.044 & 0.611 & 1.659 & -0.068 \\
\hline & $\mathrm{Zn}$ & 1.733 & 2.109 & 0.288 & 0.088 & 0.376 & 0.841 & -0.066 \\
\hline & $\mathrm{Cd}$ & 1.482 & 2.285 & 0.499 & 0.304 & 0.803 & 1.358 & -0.066 \\
\hline & As & 1.285 & 2.094 & 0.739 & 0.070 & 0.809 & 1.490 & -0.243 \\
\hline & $\mathrm{Hg}$ & 1.780 & 2.191 & 0.248 & 0.163 & 0.411 & 0.656 & -0.079 \\
\hline \multirow{6}{*}{ 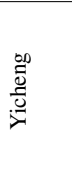 } & $\mathrm{Cu}$ & 1.971 & 2.067 & 0.036 & 0.060 & 0.096 & 0.168 & -0.007 \\
\hline & $\mathrm{Pb}$ & 1.900 & 2.062 & 0.104 & 0.058 & 0.162 & 0.646 & -0.005 \\
\hline & $\mathrm{Zn}$ & 1.729 & 2.112 & 0.275 & 0.108 & 0.383 & 1.275 & -0.016 \\
\hline & $\mathrm{Cd}$ & 1.800 & 2.103 & 0.201 & 0.102 & 0.303 & 0.829 & -0.023 \\
\hline & As & 1.659 & 2.076 & 0.343 & 0.075 & 0.418 & 1.224 & -0.036 \\
\hline & $\mathrm{Hg}$ & 1.507 & 2.084 & 0.497 & 0.080 & 0.577 & 1.243 & -0.096 \\
\hline
\end{tabular}

compared to the basic statistics for these samples. In addition, the data given in Table 3 indicate that these elements have different orders depending on whether they are sorted by $\Delta \alpha, \Delta f(\alpha)$, or $\tau^{\prime \prime}(1)$ values, all of which reflects differing aspects of the multifractality of these data. Here we consider that $\Delta \alpha, \Delta f(\alpha)$, and $\tau^{\prime \prime}(1)$ have equal weightings that reflect the overall multifractality of the data from the study area. As such, the ordering of these elements by $\Delta \alpha, \Delta f(\alpha)$, or $\tau^{\prime \prime}(1)$ involved the summation of these values, with the summed ordering then sorted again to compare the overall multifractality of these data.

The overall amount of multifractality within the soil geochemical data for the Daxing area decreases as follows: $\mathrm{Pb}>\mathrm{Cd}>\mathrm{As}>\mathrm{Zn}>\mathrm{Hg}>\mathrm{Cu}$, whereas the overall amount of multifractality within the soil geochemical data for the Yicheng area decreases as follows: $\mathrm{Hg}>\mathrm{As}>\mathrm{Zn}>\mathrm{Cd}>\mathrm{Pb}>\mathrm{Cu}$. The overall orders indicate that the $\mathrm{Pb}$ and $\mathrm{Hg}$ soil data have the highest degree of multifractality in the Daxing and Yicheng areas, respectively, whereas $\mathrm{Cu}$ has the weakest multifractality irrespective of the area.

We further analysed the spatial distribution of contamination within soils from the Daxing and Yicheng areas and evaluated whether there is any significant correlation between multifractality and anthropogenic activity. Filled contour maps showing the distribution of $\mathrm{Pb}$ in the Daxing area and $\mathrm{Hg}$ and $\mathrm{Cu}$ in the Yicheng area were calculated using inverse distance-weighted interpolation (Figs. 4, 5, 6). These figures show that areas with elevated levels of $\mathrm{Pb}$ contamination within the Daxing area are correlated with the location of industrial factories, although interestingly the areas in the upper and lower left-hand side of Fig. 4 contain factories but not elevated concentrations of $\mathrm{Pb}$. This indicates that the $\mathrm{Pb}$ concentrations in these soils may be dependent on both the presence and type of industry in this area, with some industries polluting more than others, either as a direct result of the differing industries present in this area or as a result of differing approaches to lessening environmental impacts. In comparison, the $\mathrm{Hg}$ contamination in the Yicheng area is definitely spatially correlated with the location of agricultural 
Table 3. Elements sorted by multifractal parameters and basic statistic indices.

\begin{tabular}{|c|c|c|c|c|c|c|}
\hline \multirow[t]{3}{*}{ Town } & \multirow[t]{3}{*}{ Element } & \multicolumn{5}{|c|}{ Order } \\
\hline & & \multirow{2}{*}{$\frac{\text { Basic statistics }}{\mathrm{CV}^{\mathrm{a}}}$} & \multicolumn{4}{|c|}{ Multifractal parameters } \\
\hline & & & $\Delta \alpha$ & $\Delta f(\alpha)$ & $\tau^{\prime \prime}(1)$ & Overall $^{\mathrm{b}}$ \\
\hline \multirow{6}{*}{ 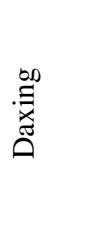 } & $\mathrm{Cu}$ & 6 & 6 & 4 & 6 & 6 \\
\hline & $\mathrm{Pb}$ & 5 & 3 & 1 & 1 & 1 \\
\hline & $\mathrm{Zn}$ & 4 & 5 & 5 & 2 & 4 \\
\hline & $\mathrm{Cd}$ & 2 & 2 & 3 & 3 & 2 \\
\hline & As & 1 & 1 & 2 & 5 & 3 \\
\hline & $\mathrm{Hg}$ & 3 & 4 & 6 & 4 & 5 \\
\hline \multirow{6}{*}{ 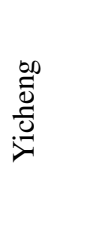 } & $\mathrm{Cu}$ & 5 & 6 & 6 & 5 & 6 \\
\hline & $\mathrm{Pb}$ & 6 & 5 & 5 & 6 & 5 \\
\hline & $\mathrm{Zn}$ & 4 & 3 & 1 & 4 & 3 \\
\hline & $\mathrm{Cd}$ & 3 & 4 & 4 & 3 & 4 \\
\hline & As & 2 & 2 & 3 & 2 & 2 \\
\hline & $\mathrm{Hg}$ & 1 & 1 & 2 & 1 & 1 \\
\hline
\end{tabular}

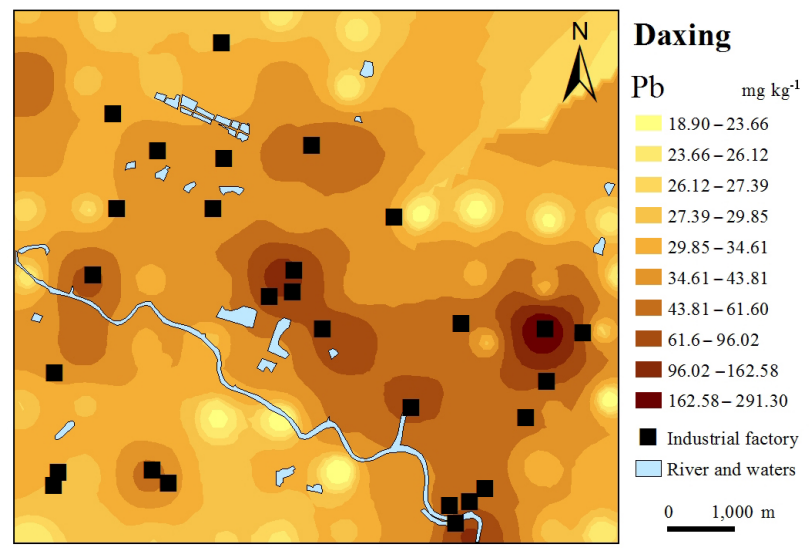

Figure 4. Filled contour map generated by inverse distanceweighted interpolation showing the spatial distribution of soil $\mathrm{Pb}$ concentrations in the Daxing area (generated using the Inverse Distance Weighting spatial analyst tool of the ArcGIS software package).

breeding facilities. Although the mean concentrations of $\mathrm{Hg}$ in soils are greater in the Daxing area, all of the multifractal parameters determined during this study $(\Delta \alpha, \Delta f(\alpha)$, and $\left.\tau^{\prime \prime}(1)\right)$ indicate that the $\mathrm{Hg}$ data in the Daxing area have a lower multifractality than the $\mathrm{Hg}$ data in the Yicheng area. The Yicheng area is heavily agricultural, meaning that the agricultural activities in this area may be both concentrating $\mathrm{Hg}$ and contaminating soils. In addition, although the mean concentrations of $\mathrm{Hg}$ in the Yicheng area are lower than in the soils in the Daxing area, the former has a higher maximum concentration than the latter, and both areas have significant $\mathrm{Hg}$ contamination. Indeed, the contamination in the Yicheng

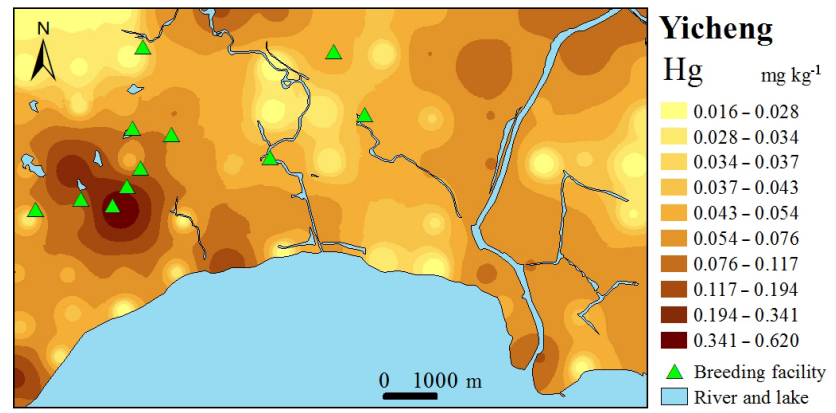

Figure 5. Filled contour map generated by inverse distanceweighted interpolation showing the spatial distribution of soil $\mathrm{Hg}$ concentrations in the Yicheng area (generated using the Inverse Distance Weighting spatial analyst tool of the ArcGIS software package).

area may be of more concern than the contamination in the Daxing area, as the agricultural activity in the Yicheng area may lead to greater human intake of $\mathrm{Hg}$ than from the soils in the mainly industrial Daxing area, a factor that could lead to serious health issues (e.g. Minamata disease) caused by the potential concentration of $\mathrm{Hg}$ up the food chain. This indicates that soils in both areas may well require control and remediation.

This distribution of soils with elevated concentrations of $\mathrm{Hg}$ also contrasts with the symmetrical distribution and weakest multifractality for $\mathrm{Cu}$ within the Yicheng area (Figs. 3, 5, 6). Here, we generated a correlation matrix that compares the relationship between the spatial density of breeding locations in the Yicheng area (Fig. 7) and filled contour maps showing the distribution of $\mathrm{Hg}$ (Fig. 5) and $\mathrm{Cu}$ (Fig. 6) in this region to identify whether there are any spa- 


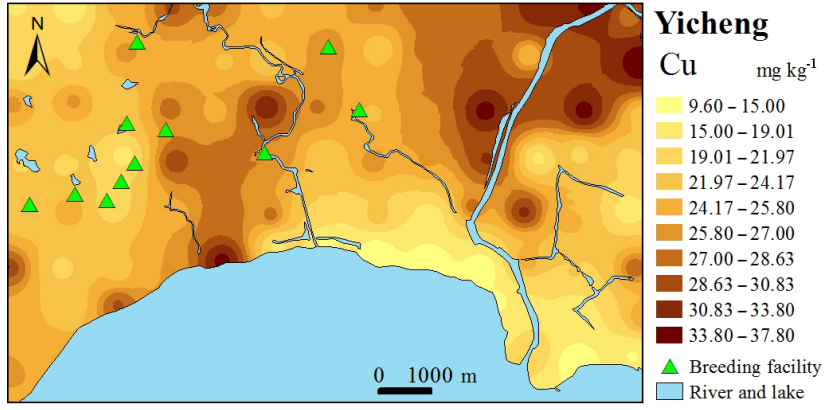

Figure 6. Filled contour map generated by inverse distanceweighted interpolation showing the spatial distribution of soil $\mathrm{Cu}$ concentrations and the location of breeding facilities in the Yicheng area (generated using the Inverse Distance Weighting spatial analyst tool of the ArcGIS software package).

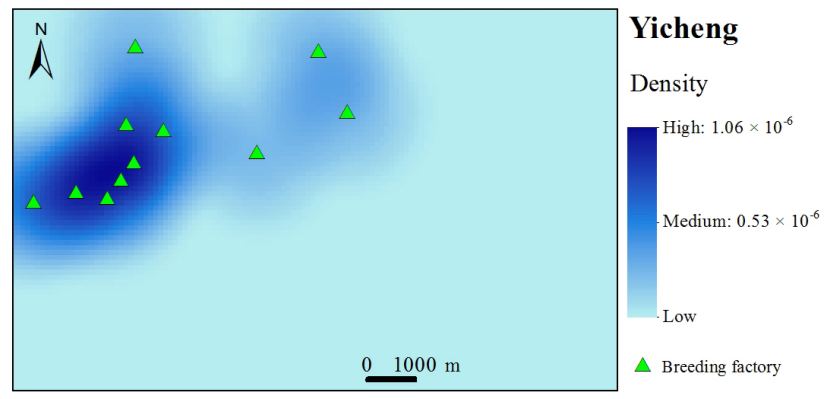

Figure 7. Density map of breeding facilities in the Yicheng area (generated using the Kernel Density spatial analyst tool of the ArcGIS software package).

tial correlations between the location of agricultural facilities and areas containing soils with elevated heavy metal concentrations (Table 4). The correlation matrix shows a significant correlation between agricultural facilities and high concentrations of $\mathrm{Hg}$ (coefficient of correlation $=0.434$ ), whereas the location of these agricultural breeding facilities and areas of high $\mathrm{Cu}$ concentrations either have no relationship or are negatively correlated (coefficient of correlation $=-0.064$ ). This indicates that very little $\mathrm{Cu}$ has been anthropogenically added to (or removed from) the soils in the Yicheng area, suggesting that these soils may contain only natural background concentrations of $\mathrm{Cu}$ and that the breeding facilities in this area do not produce significant $\mathrm{Cu}$ contamination. The negative correlation coefficient, symmetrical distribution, and weakest multifractality of $\mathrm{Cu}$ give one clue as to the spatial relationship between $\mathrm{Cu}$ contamination and the river in the right-hand side of Fig. 6. This may suggest a nonanthropogenic source (e.g. flooding causing the deposition of $\mathrm{Cu}$ or some other relationship between water and $\mathrm{Cu}$ contamination) for some of the slightly elevated $\mathrm{Cu}$ concentrations in this region. In addition, the fact that some breeding facilities are not associated with significant $\mathrm{Hg}$ contamination (Fig. 5) suggests again that, although there is a relationship
Table 4. Correlation matrix comparing the breeding facility density map and the filled contour maps for $\mathrm{Hg}$ and $\mathrm{Cu}$ data for the Yicheng area (calculated using the Band Collection Statistics spatial analyst tool of the ArcGIS software package).

\begin{tabular}{lrrr}
\hline Layers & Layer 1 & Layer 2 & Layer 3 \\
\hline Layer 1 & 1.000 & 0.434 & -0.064 \\
Layer 2 & 0.434 & 1.000 & -0.464 \\
Layer 3 & -0.064 & -0.464 & 1.000 \\
\hline
\end{tabular}

Layer 1: density map of breeding factories of Yicheng area (Fig. 7).

Layer 2: filled contour map of $\mathrm{Hg}$ concentrations of Yicheng area (Fig. 5).

Layer 3: filled contour map of $\mathrm{Cu}$ concentrations of Yicheng area (Fig. 6).

between the presence of these facilities and contamination, it may be that the $\mathrm{Hg}$ contamination in this area reflects differing types of breeding facilities or differing approaches to lessening environmental impacts.

These results indicate that multifractal modelling and the associated generation of multifractal parameters are a useful approach in the evaluation of heavy metal pollution in soils and the identification of major element of heavy metal contamination. In addition, the differing orders of the multifractality of the geochemical data for soils within the Daxing area and Yicheng area are indicative of a significant difference in the geochemical characteristics (and heavy metal pollution) in the soils within these two areas. This indicates that differing treatment strategy and clean-up approaches to remediating these two polluted areas are needed, rather than a single cover-all strategy and approach to the remediation of heavy metal pollution. A significant number of different remediation approaches can be used to resolve the issues of heavy metal soil contamination (e.g. Bech et al., 2014; Koptsik, 2014). Although somewhat beyond the scope of this study, the multi-element nature of the contamination in the Daxing area means that physical and chemical approaches to remediation (i.e. soil removal, soil vitrification, soil consolidation, electroremediation, or soil washing) are probably well suited for the remediation of heavy-metal-contaminated soil in this region (especially $\mathrm{Pb}$ ). In comparison, the differing (i.e. Hg-dominated) type of soil contamination in the Yicheng area could be more efficiently treated using microremediation and phytoremediation, primarily as the agriculture in this area requires a rapid reduction in the mobility and biological availability of heavy metals in the soils (Mulligan et al., 2001; Wang and Greger, 2006). In addition, the source of the $\mathrm{Hg}$ contamination (e.g. fertilizer, fodder, pesticides, water) remains unclear. Identifying this source is also beyond the scope of this paper although it is also clearly an area for future research, as the identification of the source or sources of this contamination may prevent the future heavy metal pollution of soils in this region. 


\section{Conclusions}

Multifractal modelling and the resulting multifractal parameters in this paper indicate that the soils from the Daxing area have stronger multifractality for $\mathrm{Cu}, \mathrm{Pb}, \mathrm{Zn}, \mathrm{Cd}$, and $\mathrm{As}$ than soils from the Yicheng area, although the latter have relatively strong multifractality for $\mathrm{Hg}$. The ordering of values for the multifractal parameters $\Delta \alpha, \Delta f(\alpha)$, and $\tau^{\prime \prime}(1)$ indicates that the degree of multifractality for the geochemical data for soils within the Daxing area descends as follows: $\mathrm{Pb}>\mathrm{Cd}>\mathrm{As}>\mathrm{Zn}>\mathrm{Hg}>\mathrm{Cu}$; within the Yicheng area it descends as follows: $\mathrm{Hg}>\mathrm{As}>\mathrm{Zn}>\mathrm{Cd}>\mathrm{Pb}>\mathrm{Cu}$. In addition, $\mathrm{Cu}$ concentrations in soils in the Yicheng area may still have their original (i.e. natural) distribution and may not have been influenced by human activities. These data indicate that the industrial activity concentrated in the Daxing area generates multi-element heavy metal soil contamination, whereas the agricultural activity concentrated in the Yicheng area generates Hg-dominated heavy metal soil contamination. The latter is important, as $\mathrm{Hg}$ contamination can cause serious health issues (e.g. Minamata disease), and the soils in this area may require remediation, especially as $\mathrm{Hg}$ can be concentrated up the food chain and the Yicheng area is heavily agricultural, indicating that this activity may both be concentrating $\mathrm{Hg}$ and contaminating soils in this area.

The results presented here indicate that multifractal modelling can be a useful approach in the evaluation of heavy metal pollution in soils and the identification of problematic heavy metals that need remediation in the research area.

\section{Data availability}

The raw data used in this paper are not publicly accessible.

Acknowledgements. This research was financially supported by funds from the Chinese Academy of Science "Light of West China" Program, the Fundamental Research Funds for the Central Universities, and the Program for New Century Excellent Talents in University (grant no. NCET-10-0324).

Edited by: J. M. Miras Avalos

Reviewed by: J. Miranda and two anonymous referees

\section{References}

Albanese, S., De Vivo, B., Lima, A., and Cicchella, D.: Geochemical background and baseline values of toxic elements in stream sediments of Campania region (Italy), J. Geochem. Explor., 93, 21-34, 2007.

Armstrong, H. E. L., Corns, W. T., Stockwell, P. B., O'Connor, G., Ebdon, L., and Evans, E. H.: Comparison of afs and icp-ms detection coupled with gas chromatography for the determination of methylmercury in marine samples, Anal. Chim. Acta, 390, 245-253, 1999.
Bech, J., Korobova, E., Abreu, M., Bini, C., Chon, H. T., and PérezSirvent, C.: Soil pollution and reclamation, J. Geochem. Explor., 147, 77-79, 2014.

Buczkowski, S., Hildgen, P., and Cartilier, L.: Measurements of fractal dimension by box-counting: a critical analysis of data scatter, Physica A, 252, 23-34, 1998.

Caniego, F. J., Espejo, R., Martın, M. A., and José, F. S.: Multifractal scaling of soil spatial variability, Ecol. Model., 182, 291-303, 2005.

Cheng, Q.: The perimeter-area fractal model and its application to geology, Math. Geol., 27, 69-82, 1995.

Cheng, Q.: The gliding box method for multifractal modeling, Comput. Geosci., 25, 1073-1079, 1999.

Cheng, Q.: Selection of Multifractal Scaling Breaks and Separation of Geochemical and Geophysical Anomaly, Journal of China University of Geosciences, 1, 54-59, 2001.

Cheng, Q.: Multifractal modelling and spectrum analysis: Methods and applications to gamma ray spectrometer data from southwestern Nova Scotia, Canada, Sci. China. Ser. D, 49, 283-294, 2006.

Dathe, A., Tarquis, A. M., and Perrier, E.: Multifractal analysis of the pore- and solid-phases in binary two-dimensional images of natural porous structures, Geoderma, 134, 318-326, 2006.

Deng, J., Wang, Q., Wan, L., Liu, H., Yang, L., and Zhang, J.: A multifractal analysis of mineralization characteristics of the Dayingezhuang disseminated-veinlet gold deposit in the Jiaodong gold province of China, Ore Geol. Rev., 40, 54-64, 2011.

Gómez-Ariza, J. L, Sánchez-Rodas, D., Giráldez, I., and Morales, E.: A comparison between ICP-MS and AFS detection for arsenic speciation in environmental samples, Talanta, 51, 257-268, 2000.

Gonçalves, M. A.: Characterization of Geochemical Distributions Using Multifractal Models, Math. Geol., 33, 41-61, 2000.

Guillén, M. T., Delgado, J., Albanese, S., Nieto, J. M., Lima, A., and De Vivo, B.: Environmental geochemical mapping of Huelva municipality soils (SW Spain) as a tool to determine background and baseline values, J. Geochem. Explor., 109, 59-69, 2011.

Jennane, R., Ohley, W. J., Majumdar, S., and Lemineur, G.: Fractal analysis of bone X-ray tomographic microscopy projections, IEEE T. Med. Imaging, 20, 443-449, 2001.

Jiang, G. B., Shi, J. B., and Feng, X. B.: Mercury Pollution in China, Environ. Sci. Technol., 40, 3672-3678, 2006.

Koptsik, G. N.: Modern approaches to remediation of heavy metal polluted soils: A review, Eurasian Soil. Sci.+, 47, 707-722, 2014.

Kravchenko, A., Boast, C., and Bullock, D.: Multifractal analysis of soil spatial variability, Agron. J., 91, 1033-1041, 1999.

Leyval, C., Turnau, K., and Haselwandter, K.: Effect of heavy metal pollution on mycorrhizal colonization and function: physiological, ecological and applied aspects, Mycorrhiza, 7, 139-153, 1997.

Lima, A., De Vivo, B., Cicchella, D., Cortini, M., and Albanese, S.: Multifractal IDW interpolation and fractal filtering method in environmental studies: an application on regional stream sediments of (Italy), Campania region, Appl. Geochem., 18, 1853-1865, 2003.

Lopes, R. and Betrouni, N.: Fractal and multifractal analysis: A review, Med. Image Anal., 13, 634-649, 2009. 
Luo, C., Liu, C., Yan, W., Xiang, L., Li, F., Gan, Z., and Li, X.: Heavy metal contamination in soils and vegetables near an ewaste processing site, South China, J. Hazard. Mater., 186, 481490, 2011

McGrath, D., Zhang, C., and Carton, O. T.: Geostatistical analyses and hazard assessment on soil lead in Silvermines area, Ireland, Environ. Pollut., 127, 239-248, 2004.

Mulligan, C., Yong, R., and Gibbs, B. F.: Remediation technologies for metal-contaminated soils and groundwater: an evaluation, Eng. Geol., 60, 193-207, 2001.

Pascual, M., Ascioti, F., and Caswell, H.: Intermittency in the plankton: a multifractal analysis of zooplankton biomass variability, J. Plankton Res., 17, 167-168, 1995.

Salvadori, G., Ratti, S. P., and Belli, G.: Fractal and multifractal approach to environmental pollution, Environ. Sci. Pollut. R., 4, 91-98, 1997.

Schertzer, D., Lovejoy, S., Schmitt, F., Chigirinskaya, Y., and Marsan, D.: Multifractal Cascade Dynamics and Turbulent Intermittency, Fractals, 5, 427-471, 2011.

Tarquis, A. M., Mcinnes, K. J., Key, J. R., Saa, A., García, M. R., and Díaz, M. C.: Multiscaling analysis in a structured clay soil using 2D images, J. Hydrol., 322, 236-246, 2006.

Thomas, K. and Stefan, S.: Estimate of heavy metal contamination in soils after a mining accident using reflectance spectroscopy, Environ. Sci. Technol., 36, 2742-2747, 2002.

Wang, Y. and Greger, M.: Use of iodide to enhance the phytoextraction of mercury-contaminated soil, Sci. Total. Environ., 368, 30-39, 2006.
Wang, Y. P., Shi, J. Y., Wang, H., Lin, Q., Chen, X. C., and Chen, Y.X.: The influence of soil heavy metals pollution on soil microbial biomass, enzyme activity, and community composition near a copper smelter, Ecotox. Environ. Safe., 67, 75-81, 2007.

Wendt, H., Roux, S. G., Jaffard, S., and Abry, P.: Wavelet leaders and bootstrap for multifractal analysis of images, Signal Process., 89, 1100-1114, 2009.

Xie, S., Cheng, Q., Xing, X., Bao, Z., and Chen, Z.: Geochemical multifractal distribution patterns in sediments from ordered streams, Geoderma, 160, 36-46, 2010.

Yuan, F., Li, X., Jowitt, S. M., Zhang, M., Jia, C., Bai, X., and Zhou, T.: Anomaly identification in soil geochemistry using multifractal interpolation: A case study using the distribution of $\mathrm{Cu}$ and $\mathrm{Au}$ in soils from the Tongling mining district, Yangtze metallogenic belt, Anhui province, China, J. Geochem. Explor., 116-117, 2839, 2012.

Yuan, F., Li, X., Zhou, T., Deng, Y., Zhang, D., Xu, C., Zhang, R., Jia, C., and Jowitt, S. M.: Multifractal modelling-based mapping and identification of geochemical anomalies associated with $\mathrm{Cu}$ and Au mineralisation in the NW Junggar area of northern Xinjiang Province, China, J. Geochem. Explor., 154, 252-264, 2015.

Zuo, R., Carranza, E. J. M., and Cheng, Q.: Fractal/multifractal modelling of geochemical exploration data, J. Geochem. Explor., $122,1-3,2012$. 